\title{
Peningkatan Kesiapan Kerja melalui Pelatihan Efikasi Diri dalam Bidang Pekerjaan pada Calon Tenaga Kerja
}

\author{
Tekad Wahyono \\ Universitas Wangsa Manggala
}

\begin{abstract}
The aim of this research is to examine the effectiveness of occupational self efficacy training in improving work readiness among work applicants. The proposed hypothetis is: there is a work readiness differences between a group where the occupational self efficacy training is given and a group without self efficacy training. A group given occupational selfefficacy training shows higher work readiness.

Subjects were 42 people and were divided into two groups (experimental group and control group) af random. The research applies the pretest posttest control group design. Data wers collected from work readiness scale and analyzed by one way anova.

The result of the analysis indicates that $F$ (between groups) $=65.142, p=0.000 \quad(p<0.010)$. This means that there is a significant work readiness difference between the experimental group with occupational self-efficacy training and control group without occupational selfefficacy training. The mean of work readiness in the experimental group is significantly higher than the mean in the control group.
\end{abstract}

Key words: occupational self-efficacy training, work readiness

\section{Pendahuluan}

$D^{a}$ ala dari BPS (2001) menunjukkan bahwa jumlah pengangguran d Indonesia pada tahun 2000 sebesar 5.871 .956 orang, yang berdasarkan tingkat pendidikannya tamatan Perguruan Tinggi sebesar 278.710 orang. Penganggur dengan tingkat pendidikan Perguruan Tinggi mempunyai beban lebih tinggi karena harapan dan pandangan masyarakat terhadap mereka lebih tinggi daripada tamatan di bawahnya, sehingga upaya-upaya untuk mengalasi pengangguran pada level ini perlu ditingkatkan.

Permasalahan ketenagakerjaan menyangkut berbagai aspek kehidupan, tidak hanya aspek ekonomi, tetapi juga meluas ke permasalahan sosial dan emosi, sehingga

pertu dilakukan langkah -langkah antisipasi dari berbagai pihak, baik pemerinlah, dunia usaha dan terulama oleh individu yang bersangkutan. Hal tersebut berarti bahwa individu yang akan memasuki dunia kerja harus mempunyai sejurnlah kesiapan, baik dari segi pendidikan, ketrampilan maupun psikologis.

Permasalahan kerja perlu mendapatkan perhatian secara serius. Perhatian terhadap masalah tersebut juga harus dimulai sejak dini, yaitu sejak anak mulai memahami kerja dan mengalami proses pengembangan konsep diri. Super (dalam Wahyono, 2001) mengistilahkan tahap tersebut sebagai tahap pertumbuhan, yang terjadi sejak anak lahir sampai kira-kira usia 14 lahun. Sejak masa 
tersebut anak mulai memahami arti kerja, mengembangkan konsep diri dan ketrampilan-ketrampilan dasar dalam bekerja. Lebih lanjut disampaikan bahwa pada usia 15-24 tahun seseorang berada pada tahap eksplorasi, dengan tugas utamanya adalah peningkatan pemahaman diri, terutama kemampuan-kemampuannya, mengeksplorasi dunia kerja dan akhimya mengambil keputusan pekerjaan yang realistis.

Pemahaman dan keyakinan atas kemampuan atau kapasitas diri sering menjad; masalah bagi calon tenaga kerja remaja, sehingga perhatian terhadap masalah tersebut perlu diringkatkan. Bandura (1986) mengatakan bahwa orang dalam berperilaku sering dapat diprediksi berdasarkan keyakinan-keyakinan akan kemampuannya. Keyakinan tersebut membantu individu menentukan sesuatu yang akan dilakukannya dengan pengetahuan dan ketrampilan yang ia miliki. Kekuatan keyakinan seseorang terhadap efektivitas dirinya mempengaruhi keinginannya untuk mencoba beradaptasi dengan situasi $₫$ hadapannya. Apabila seseorang meyakini kemampuannya, maka ia dapat menggunakan pengetahuan dan ketrampilannya secara efektif untuk mengatasi situasi yang dihadapinya, termasuk dunia kerja.

Keyakinan individu datam memperkirakan kemampuan dirinya dalam melaksanakan tugas atau melakukan suatu tindakan yang diperlukan untuk mencapai suafu hasil tertentu disebut efikasi diri (Bandura, 1986, 1997). Jika keyakinan tersebut diterapkan dalam menghadapi tugas-tugas yang menyangkut pekerjaan disebut sebagai efikasi diri dalam bidang pekerjaan.

Calon tenaga kerja remaja yang mempunyai efikasi diri dalam bidang pekerjaan tinggi akan melakukan berbagai upaya untuk mempersiapkan dunia kerja agar mereka mampu melakukan tugas tersebut dengan baik. Hal tersebutditandai oleh beberapa hal, yaitu mencapai prestasi sebaik mungkin terhadap sesuatu yang dilakukannya, aktif bertanya kepada orang lain yang berpengalaman maupun mencari informasim informasi untuk menambah pengetahuan tentang dunia kerja.

Calon tenaga kerja yang berusaha keras dan aktif mempersiapkan dirinya dalam memasuki persaingan dunia kerja diharapkan mampu menjadi tenaga kerja yang siap pakai atau siap kerja. Sagir (1984) mendefinisikan tenaga kerja yang siap pakai atau siap kerja adalah tenaga kerja yang siap untuk dipakai atau dimanfaatkan dalam proses produksi sebagai tenaga kerja yang profesional dan mampu bekerja secara produktif, sehingga mampu memperoleh balas jasa yang wajar untuk dapat hidup layak dan siap menciptakan pekerjaan untuk dirinya maupun orang lain.

Hardjanto (1997) menemukan hubungan yang signifikan antara efikasi diri dengan sikap kompetitif superiority pad a siswa. Sikap kompetitif tersebut sangat diperlukan bagi calon tenaga kerja dalam menghadapi persaingan di dunia kerja. Mereka yang berada dalam situasi persaingan di dunia kerja akan terus berusaha untuk meningkatkan kapasitas dirinya agar dapat memenangkan persaingan tersebut. Usahausaha yang dilakukan calon tenaga kerja untuk meningkatkan kapasitas dirinya pada dasarnya bertujuan agar mereka siap bekerja.

Usaha-usaha untuk meningkatkan kesiapan kerja pada calon tenaga kerja sangat diperlukan, antara lain dapat dilakukan melatui berbagai pelatihan. Bernadin dan Russel (1998) mengemukakan bahwa pelatihan merupakan prosedur yang sistematis untuk meningkatkan perfomansi kerja, yang digunakan untuk mengatasi tugas-tugas yang dihadapi sekarang maupun tugas-tugas di masa yang akan datang. Berbagai penelitian menunjukkan bahwa pelatihan mampu untuk meningkatkan pengetahuan, ketrampilan, sikap dan perilaku serta kepribadian seseorang.

Pelatihan khusus untuk mempersiapkan calon tenaga kerja untuk menghadapi dunia 
kerja perlu dilakukan dengan tujuan utama aga mereka meyakini kemampuan-kernampuan yang dimilikinya, aktif melakukan upaya-upaya untuk memasuki dunia kerja dan mempunyai motivasi, komitmen dan daya juang yang tinggi dalam menghadapi persaingan di dunia keja. Pelatihan yang bertujuan untuk meningkatkan keyakinan terhadap pengetahuan, kemampuan maupun ketrampilan calon tenaga kerja sehingga mampu menghadapi tugas-tugas dalam dunia kerja serta meningkatkan komitmen, motivasi dan kerja keras calon tenaga kerja disebut pelatihan efkasi diri dalam bidang pekerjaan. Pelatihan tersebut terdin dari enam materi, yaitu: (1) perkenalan, penjelasan tujuan pelatihan, prinsip-prinsip belajar orang dewasa, jalur-jalur belajar dan kontrak pelatihan; (2). eksplorasi masalahmasalah pekerjaan; (3). target masa depan; (4). penyesuaian target dengan kondisi diri; (5). aplikasi bekal diri I dan II dan (6) motivasi dan perencanaan tindakan.

Pelatihan efikasi diri dalam bidang pekerjaan berisi materi-materi yang bertujuan agar calon tenaga kerja menyadari kapasitas dirinya, sehingga tidak ragu untuk menghadapi dunia kerja. Calon tenaga kerja yang mengikuti pelatihan efikasi diti dalam bidang pekerjaan diharapkan mempunyai efikasi diri yang tinggi.

Orang yang memiliki efikasi diri tinggi yakin bahwa in mampu berperilaku tertentu untuk mendapatkan hasil yang diinginkan pada situasi yang sedang dihadapinya, lebih giat dan tekun dalam berusaha (Bandura, 1997). Hal tersebut berarti bahwa calon tenaga kerja yang mempunyai efikasi diri dalam bidang pekerjaan tinggi mampu mengarahkan perilakurya sesuai tuntutan di dunia kerja, berusaha keras mempersiapkan diri agar mereka yakin dalarn memasuki dunia kerja, atau dapat dikatakan siap untuk bekerja. Berdasarkan uraian tersebut, tujuan yang ingin dicapai dalarn penelitian ini adalah untuk mengetahui efektivitas pelatihan efikasi diri dalam bidang pekerjaan untuk meningkatkan kesiapan kerja caion tenaga kerja.

Hipotesis utama yang diajukan dalam penelitian ini ada tiga, yaitu:

Hipotesis 1 :ada perbedaan kesiapan kerja antara kelompok eksperimen yang diberi pelatihan efikasi diri dalam bidang pekerjaan dan kelompok kontrol yang tidak diberi pelatihan efikasi diri terhadap pekerjaan. Kesiapan kerja kelompok eksperimen yang diberi pelatihan efikasi diri dalam bidang pekerjaan lebih tinggi dari pada kelompok kontrol yang tidak diberi pelatihan efikasi diri dalam bidang pekerjaan.

Hipotesis 2: ada perbedaan kesiapan kerja antara pengukuran awal (pretest) dengan peng-ukuran akhir (posttest) karena pemberian pelatihan efikasi diri dalam bidang pekerjaan. Kesiapan kerja pada pengukuran akhir (posttest) lebih tinggi datipada pengukuran awal (pretest).

Hipotesis 3: ada interaksi kesiapan kerja antar kelompok (eksperimen dan kontrol) dan pengukuran ulangan (pretest dan posttest) akibat pemberian pelatihan efikasi diri dalam bidang pekerjaan.

\section{Metode}

\section{Rancangan Eksperimen}

Rancangan eksperimen yang digunakan dalam penelitian ini adalah The PretestPosttest Control Group Design (Cook \& Campbell, 1979). Diagram desainnya seperti yang terlihat berikut ini.

\begin{tabular}{|c|c|c|c|}
\hline$R$ & 01 & $X$ & $O 2$ \\
\hline$R$ & 03 & - & $O 4$ \\
\hline
\end{tabular}

\section{Keterangan:}

\section{$\mathrm{R} \quad$ : random assignment}

01 \& 03: pretest ( Skala Kesiapan Kerja )

O2 \& 04: posttest ( Skala Kesiapan Kerja )

$X \quad$ : perlakuan ( pelatihan efikasi diri dalam bidang pekerjaan ).

Rancangan penelitian ini menutut Cook dan Campbell (1979) memiliki beberapa kelemahan yang dapat mengganggu validitas internal, yaitu faktor seleksi, kematangan, interaksi seleksi dan kematangan, testing, 
regresi statistik, instrumentasi dan imitasi perlakuan. Menurut mereka kelemahankelemahan tersebut dapat diatasi jika pembagian kelompok dilakukan secara random.

\section{Subjek Penelitian}

Subjek penelitian mempunyai ciri-ciri sebagai berikut :

1. Pendidikan : mahasiswa Fakultas Psikologi sebuah P.T swasta semester akhir.

2 Jenis kelamin: laki-laki dan perempuan.

3. Usia : 22 - 27 tahun.

4. Jumlah : 42 orang yang terbagi menjadi 2 (dua ) kelompok, yaitu kelompok eksperimen sejumlah 21 orang dan kelompok kontrol sebanyak 21 orang.

Subjek yang dilkutkan dalam peiatihan efikasi diri dalam bidang pekerjaan adalah yang mempunyai nilal kesiapan kerja dalam kategori sedang (43-60) dan rendah (<43). Dari 76 peserta yang mendaftar terdapat 52 orang yang mempunyai kesiapan kerja sedang dan 12 orang yang masuk kategori rendah. Peserta yang masuk kategori rendah diambil semua, sedangkan dari kategori sedang diambil 38 orang, sehingga jumlah subjek penelitian sebanyak 50 orang dan dibagi menjadi dua kelompok (kelompok eksperimen dan kontrol) secara random (random assignment) menggunakan kertas gulungan kecil. Dari 50 subjek tersebut ternyata pada masing-masing kelompok terdapat empat peserta yang lidak hadir, sehingga jumlah peserta yang mengikuti penelitian dari awal sampai akhir adalah 21 orang untuk kelompok eksperimen dan 21 orang untuk kelompok kontrol.

\section{Alat Pengumpul Data}

Instrumen yang digunakan untuk pengumpulan data dalam penelitian ini adalah Skala Kesiapan Kerja. Skala Kesiapan Kerja terdiri dari 2 aspek utama sesuai teori Hersey dan Blanchard (1993) yaitu berisi kemam-puan dan kemauan. Kemampuan berisi penge- tahuan, keahlian atau ketrampilan yang dimilik untuk memasuki dunia kerja dan kemampuan untuk mengatasi persoalan-persoalan yang muncul dalam memasuki dunia kerja. Kemauan berisi keyakinan diri, bekerja sama dan bersosialisasi, kerja keras, tanggung jawab, komitmen dan motivasi yang kuat untuk memasukl dunia kerja.

Model skala yang digunakan adalah Rating yang Dijumlahkan dari Likert dengan lima alternatif jawaban, yaltu: Sangat Sesuai (SS), Sesuai (S), Cukup Sesuai (CS), Tidak Sesuai (TS) dan Sangat Tidak Sesual (STS). Pedoman penilaiannya bergerak dari $5 \mathrm{ke} 1$ untuk aitem fiavourable dan 1 ke 5 untuk aitem unfiavourable. Nilai akhir merupakan penjumlahan nilai-nilai yang diperoleh pada setiap aitem.

Uji coba alat ukur dilakukan terhadap subjek yang mempunyal cirri-ciri yang sama dengan subjek penelitian. Azwar (1998) menyatakan bahwa standard koefisien validitas sebesar 0,300 dianggap cukup memuaskan, sehingga pedoman tersebut diterapkan dalam penelitian ini. Angka validitas aitem dalam uf coba alat ukur ini bergerak dari $-0,132-0,523$. Setelah dilakukan pengoreksian korelasi aitem-total dan menggunakan pedoman aitem yang valld sebesar 0,300 , altem yang dinyalakan valid bergerak antara 0,336-0,621. Hasil reliabilitas alat ukur diketahui dengan menggunakan teknik konsistensi intemal (singletrial administration) formula Alpha (a ) dari Cronbach. Alasannya adalah bahwa melalui teknik tersebut skala dapat dibelah sesuai jumlah aitemnya, sehingga jumlah aitem dalam setiap belahan sama dan seimbang (Azwar, 1998). Hasil reliabilitas dari 15 aitem yang valid menunjukkan koefisien reliabilitas Alpha sebesar á $=0,801$.

\section{Pelaksanaan Penelitian}

Penelitian dilaksanakan setelah ujj coba alat ukur penelitian dilakukan dan pembuatan modul pelatihan. Lokasi Penelitian berada di Ruang 109 Fakultas Psikologi Unwama bekerja sama dengan Biro Layanan Psikologi P 
Yogyakarta. Jadwal penelitian selengkapnya terliha: dalam Tabel 1.

Tabel 1

Prosedur Penelitian
Metode Analisis Data

Dała yang diperoleh dianalisis dengan seknik statistic Anava 1 Jalur Mixed 1 Factor untuk mengezahui perbedaan rerata ke-lompok

\begin{tabular}{|c|c|c|c|c|}
\hline No. & Tanggal & Materi & Wa & aktu \\
\hline \multirow[t]{2}{*}{1.} & 1227 Agustus 2002 & Pemasangan Pengumuman Pelatihan, Pendaftaran & $09: 00$ & $13: 00$ \\
\hline & & Peserta dan Pretest & & \\
\hline \multirow[t]{2}{*}{2.} & 28 Agustus 2002 & Pengumuman Pembagian Kelompok Eksperimen dan & 09.00 & $14: 00$ \\
\hline & & Kontrol. & & \\
\hline \multirow[t]{4}{*}{3.} & 28 Agustus 2002 & Pelaksanaan Penelitian Hari ke I & $14: 00$ & selesai \\
\hline & & (Materi: Perkena|an, Penjelasan Tujuan Pelatihan, & & \\
\hline & & Prinsip-prinsip Belajar Orang Dewasa, Kontrak Pelatihan & & \\
\hline & & dan Eksplorasi Masalah-masalah Pekerjaan) & & \\
\hline \multirow[t]{3}{*}{4.} & 29 Agustus 2002 & Pelaksanaan Penelitian Hari ke s & $14: 00$ & selesal \\
\hline & & (Materi: Target Masa Depan, Penyesuaian Target dengan & & \\
\hline & & Kondisi Diri) & & \\
\hline 5. & 30 Agustus 2002 & $\begin{array}{l}\text { Pelaksanaan Penelitian Hari ke III } \\
\text { (Materi: Aplikasi Bekal Dii l) }\end{array}$ & $14: 00$ & selesai \\
\hline \multirow[t]{2}{*}{6} & 31 Agustus 2002 & $\begin{array}{l}\text { Pelaksanaan Penejtian Hari ke IV } \\
\text { (Materi: Aplikasi Bekal Diri li, Motivasi dan Perencanaan }\end{array}$ & $14: 00$ & selesat \\
\hline & & Tindakan)) & & \\
\hline \multirow[t]{3}{*}{7.} & 2 September 200 & $\begin{array}{l}\text { Postest, baik Kelompok Eksperimen maupun Kontrol, } \\
\text { dilanjutkan pelatihan kepada Kelompok Kontrol sebagai }\end{array}$ & $14: 00$ & selesai \\
\hline & & ucapan terima kasih, dengan materi dan waktu yang & & \\
\hline & & sama dengan Kelompok Eksperimen & & \\
\hline \multirow[t]{2}{*}{8.} & 3 September 5 Oktober & Tabulasi Data, Analisis Data dan Pembuatan Laporan & & - \\
\hline & 2002 & Penelitian. & & \\
\hline
\end{tabular}


eksperimen yang diberi pelatihan efikasi diri dalam bidang pekerjaan dan kelompok kontrol yang tidak diberi pelatihan efikasi diri dalam bidang pekerjaan sebelum dan sesudah diberi perlakuan. Guna mengetahui perkembangan kemajuan diri subjek selama menjalani pelatihan, maka setiap akhir sesi subjek diberi lembar pelaporan diri, pelaporan diri akhir dan perencanaan tindakan setelah mengikuti pelatihan. Fasilitas yang digunakan untuk membantu menganalisis data penelitian secara kuan-titatif adalah program SPS (Seri Program Statistik) 2000 Edisi Sutrisno Hadi dan Yuni Pamardiningsih (2000).

\section{Has in}

\section{Tabel2}

Ringkasan Hasi! Analisis

Anava 1 Jalur-Mixed 1 Faktor
Data yang telah terkumpul melalui pretes: dan posttest sebelum dianalisis meng-gunakan Anava 1 Jalur Mixed 1 Factor dilakukan uji asumsi terlebih dahulu. Uji asumsi yang diperlukan adalah uji nomalitas sebaran dan uji homogenitas variansi antar kelompok dan ukur ulang (Hadi, 2000). Dari analisis data ternyata dua uj tersebut terpenuhi. Uj Anave 1 Jalur Mixed 1 Factor dilakukan dengan: menggunakan data setara agar titik pemberangkatan pada pengukuran l (pretest) sama antara dua kelompok. RIngkasan hasil pengujian hipotesis menggunakan Anava 1 Jalur Mixed 1 Factordisajikan dalam Tabel II.

$\mathrm{U}_{\mathrm{ji}}$ lanjutan dengan menggunakan uji $\mathrm{t}$ dilakukan setelah uj $\mathrm{F}$ signifikan.Ringkasan hasil Uji-t dapat dilihat dalam Tabel III.

Tabel II di atas menunjukkan bahwa nilai $F$ antar $A=65,142, d b=(1,40)$ dengan $p=$ $0.000(p<0.010)$, berarti hipotesis yang

\begin{tabular}{cccccc}
\hline Sumber Variansi & $K$ & Db & RK & $F$ & $P$ \\
\hline AntarA & $1,352.012$ & 1 & $1,352.012$ & 65,142 & 0.000 \\
GalatAntar & 830,191 & 40 & 20,755 & - & - \\
Antar B & $1,746.298$ & 1 & $1,746.298$ & 84.140 & 0.000 \\
Inter AB & $1,352.013$ & 1 & $1,352.013$ & 65.142 & 0.000 \\
Galat Dalan & 830.189 & 40 & 20,755 & - & - \\
\hline Total & $8,110.703$ & 83 & - & - & - \\
\hline
\end{tabular}

Tabel 3

Ringkasan Hasil Ujit

\begin{tabular}{cccc}
\hline Surriber & Perbedaan & $p$ & Statug \\
\hline A1 A2 & 8.071 & 0.000 & * \\
B1 B2 & -9.173 & 0.000 & * \\
A1B1 A1B2 & -12.193 & 0.000 & * \\
A2B1 A2B2 & -0.779 & 0.534 & TS \\
A1B1 A2B1 & 0.000 & 1.000 & TS \\
A1B2 A282 & 11.414 & 0.000 & **
\end{tabular}

Catatan: - Sangat Slgnifikan 
menyatakan bahwa ada pebedaan kesiapan kerja antara kelompok eksperimen yang diberi pelatihan efikasi díri dalam bidang pekerjaan dan kelompok kontrol yang tidak diberi pelatihan efikasi diri dalam bidang pekerjaan diterima dengan sangal signifikan. Jika dilihat dari Uji-t an tar kelompokA terdapat perbedaan rerata yang sangat signifikan (rerata A1-A2 = $8.071, d b=40$ dengan $p=0.000$ ), sehingga dapat disimpukan bahwa rerata kesiapan kerja kelompok eksperimen yang diberi pelatihan efikasi diri dalam bidang pekerjaan lebih tinggi daripada kelompok kontrol yang tidak diberi pelatihan efikasi diri dalam bidang pekerjaan (rerata $\mathrm{A} 1=8.571, \mathrm{~A} 2=0.548$ ) . Dari hasil tersebut dapat disimpulkan bahwa kesiapan kerja kelompok eksperimen yang diberi pelatihan efikasi diri dalam bidang pekerjaan lebih tinggi daripada kelompok kontrol yang tidak diberi pelatihan efikasi diri dalam bidang pekerjaan.

Tabel II memperlihatkan nilai $\mathrm{F}$ antar $\mathrm{B}=$ $84.140, d b=(1,40)$ dengan $p=0.000(p<$ $0.010)$, berarti hipotesis ke dua yang menyatakan ada perbedaan kesiapan kerja antara pengukuran awal (pretest) dengan pengukuran akhir (posttest) karena pemberian pelatihan efikasi diri dalam bidang pekerjaan. Jika dilihat dari Uji-tAntar Ulangan $B$ perbedaan rerata ke dua pengukuran (oretest dan posttest) tersebut sangat signifikan (rerata $\mathrm{B} 1-\mathrm{B} 2=-9.173, \mathrm{db}=40$ dengan $p=$ 0.000 ), sehingga dapat disimpulkan bahwa rerata kesiapan kerja pada pengukuran ke dua (posttest) lebih tinggi daripada pengukuran pertama (pretest) (rerata B1 = $0.000, B 2=9.119$ ) . Dari hasil tersebut dapat disimpulkan bahwa kesiapan kerja sesudah diberi pelatihan efikasi diri dalam bidang pekerjaan lebih tinggi daripada sebelum diberi pelathan efikasi diri dalam bidang pekerjaan.

Table II juga memperlihatkan bahwa nilai $F$ Inter $A B=65.142, d b=(1,40)$ dengan $p=$ $0.000(\mathrm{p}<0.010)$, berarti hipotesis ke tiga yang menyatakan bahwa ada interaksi kesiapan kerja antara kelompok (eksperimen dan kontrol) dan pengukuran ulangan (pretest dan posttest) akibat pemberian pelatihan efikasi diri dalam bidang pekerjaan.

Hasil Uji-t 2-Jalan AB memperlihatkan bahwa perbedaan rerata antara A1B1 dan $A 1 B 2$ adalah sebesar $t=-12.193, d b=40$ dengan $p=0.000(p<0.010)$, sehingga dapat disimpulkan ada perbedaan kesiapan kerja pada kelompok eksperimen sebelum diberi pelatihan efikasi diri dalam bidang pekerjaan dan sesudah diberi pelatihan efikasi diri dalam bidang pekerjaan diterima secara sangat signifikan. Kesiapan kerja kelompok eksperimen sesudah diberi pelatihan efikasi diri dalam bidang pekerjaan lebih tinggi (rerata $=17.143)$ daripada sebelum diberi pelatihan efikasi diri dalam bidang pekerjaan (rerata $=0.000$ ).

Perbedaan rerata antara $\mathrm{A} 2 \mathrm{~B} 1$ dan $\mathrm{A} 2 \mathrm{~B} 2$ adalah sebesar $t=-0.779, d b=40$ dengan $p$ $=0.534(p>0.050)$, sehingga dapat disimpulkan tidak ada perbedaan kesiapan kerja pada kelompok kontrol sebelum diberi pelatihan efikasi diri dalam bidang pekerjaan (rerata $=0.000$ ) dan sesudah diberi pelatihan efikasi diri dalam bidang pekerjaan (rerala = 1.095) diterima.

Perbedaan rerata antara A1B2 dengan $A 2 B 2$ adalah sebesar $t=11.414, d b=40$ dengan $p=0.000(p<0.010)$, sehingga dapat disimpulkan ada perbedaan kesiapan kerja antara kelompok eksperimen dan kelompok kontrol sesudah diberi pelatihan efikasi diri dalam bidang pekerjaan diterima dengan sangat signifikan. Kesiapan kerja kelompok eksperimen yang diberi pelathan efikasi diri dalam bidang pekerjaan lebih tinggi (rerata = 17.143 ) daripada kelompok kontrol yang tidak diberi pelatihan efikasi diri dalam bidang pekerjaan $($ rerata $=1.095)$.

\section{Pembahasan}

Hasil analisis data penelitian menunjukkan bahwa semua hipotesis yang diajukan dalam penelitian ini terbukti. Terbuktinya hipotesis-hipotesis tersebut dapat disebabkan oleh keaktivan peserta pelatihan selama mengikuti pelatihan, metode pelatihan dan materi pelatihan yang tidak dapat dipisahkan 
satu dengan yang lainnya.

Peserta pelatihan terlihat aktif sejak awal sampai akhir pelatihan. Hal tersebut dapat disebabkan oleh materi-materi awal pelatihan, yaitu: penjelasan tujuan pelatihan, penggunaan prinsip-prinsip belajar orang dewasa dan ja|ur-jalur belajar serta ditandatanganinya kontrak pelatihan. Tujuan pelatihan yang ditawarkan berkaitan langsung dengan permasalahan yang mereka hadapi, yaitu masalah persiapan memasuki dunia kerja. Ketika ditanya hal-hal yang mendorong mereka ingin mengikuti pelatihan ini, hampir semua peserta mengatakan bahwa materimateri yang ditawarkan dalam pelatihan ini sangat menarik dan mereka perlukan.

Sesi Eksplorasi Masalah-masalah Pekerjaan bertujuan untuk menguji persepsi peserta tentang diri dan permasalahan kerja serta kondisi kapasitas diri dalam menghadapi situasi tersebut. Menurut Bandura (1986) dan Pajares (2002) efikasi diri yang dimiliki seseorang diawali dari persepsi tentang penciptaan dan pengembangan persepsi tentang kapasitasnya yang merupakan alat untuk mencapai tujuan dan kendali terhadap situasi-situasi yang akan dihadapi di lingkungannya. Lebih lanjut Bandura (1986) menyatakan bahwa cara seseorang berperilaku sering dapat diprediksi secara lebih baik lebih baik melalui keyakinan akan kapasitas dirinya daripada kapasitasnya tersebut secara aktual. Melalui sesi ini peserta mulai menghilangkan persepsi diri yang lama untuk diganti dengan persepsi baru yang akan dilalui pada sesi-sesi berikutnya.

Sesi permainan Lempar Gelang (Ring Toss Game) membawa peserta ke dalam pengalaman belajar tentang pentingnya penentuan target, hal-hal yang mempengaruhi dan prinsip-prinsip penentuan target yang benar. Menurut Bandura (1986) pembuatan tujuan/target akan menentukan harapan efikasi seseorang dalam mencapai sesuatu. Lebih lanjut dikemukakan bahwa hasil dari harapan sebagian besar sangat tergantung dari penilaian akan kapasitas dirinya. Menurut Pintrinch dan Schunck(1996) pembuatan tujuan akan mengarahkan perilaku seseorang agar dapat mencapai tujuan tersebut, dan efikasi diri merupakan mediator dalam pencapaian tujuan-tujuan yang ditetapkan. Pintrinch dan Schunk (1996) selanjutnya menyampaikan bahwa pembuatan tujuan-tujuan tersebut akan membantu seseorang untuk menjaga perilakunya agar lebihakurat dalam menapaki proses untuk mencapai tujuan tersebut dan menghindari ilusi terhadap ketidakmampuan diri.

Sesi Aplikasi Bekal Diri bertujuan untuk menguji realitas kemampuan dan ketrampilan yang dimiliki peserta yang berguna untuk memasuki dunia kerja. Sesi ini sekaligus bertujuan untuk membangun persepsi positif tentang kemampuan, ketrampilan dan pengetahuan yang telah dimiliki peserta selama menjalani studi, karena dengan dibangunnya persepsi positif tersebut akan menentukan tingkat motivasi, kondisi afeksi dan perilaku seseorang daripada yang secara aktual mereka miliki (Bandura, 1986, 1997). Melalui sesi ini peserta diberikan kasus-kasus di dunia kerja agar peserta mampu menerapkan bekal pengetahuan dan ketrampilan yang telah mereka pelajari selama ini. Menurut Bandura (1997) efikasi diri membantu menentukan sesuatu yang in dividu lakukan berdasarkan pengetahuan dan ketrampllan yang dimilikinya. Hal tersebut sekaligus menjelaskan mengapa perilaku seseorang dalam mencapai sesuatu sering kurang berhubungan dengan pengetahuan dan ketrampilan yang secara aktual dimilikinya. Pajares (2002b) juga menyatakan bahwa efikasi diri merupakan determinan penting dalam menerapkan pengetahuan dan ketrampilan yang diperlukan untuk melakukan sesuatu.

Sesi Motivasi bertujuan agar peserta memahami bahwa datam mencapai sesuatu perlu usaha keras dan pantang menyerah. Setelah mereka membangun harapan efikasi dan menguji bekal yang mereka miliki selama menjalankan studi, selanjutnya mereka harus tetap menjaga usaha yang dilakukan agar dapat mencapal tujuan yang telah ditetapkan. 
Melalui dibangunnya usaha keras peserta akan tetap menjaga motivasinya sampai tujuantujuannya tercapak. Efkkasi diri membantu menentukan jumlah usaha yang dilakukan seseorang dalam melakukan aktivitas pencapaian tujuan dan seberapa tabah ketika menghadapi hambatan (Pajares, 2002b).

Sesi-sesi dalam pelatihan efikasi diri dalam bidang pekerjaan membuat peserta dapat mengembangkan kebiasaan dan perilaku kerja yang positif, ketrampilan dalam berhubungan interpersonai dan perilaku pengatasan situasi-situasi daiam dunia kerja. Menurut Casey (2002) pengalaman-pengalaman yang dikakukan oleh seseorang yang bertujuan mendekatkan diri dengan kebiasaan, sikap dan perilaku serta lingkungan kerja membuat seseorang mempunyai ciri-ciri calon tenaga kerja yang mempunyai kesiapan kerja yang tinggi. Mereka memiliki kemampuan untuk bekerja dan kemauan yang kuat jika harus dihadapkan pada tugas-tugas yang diberikannya (Hersey dan Blanchard, 1993). Ca lon tenaga kerja yang mempunyai kemampuan dan dipersepsi positif serta kemauan yang kuat untuk melaksanakan tugas-tugas dalam pekerjaan dikatakan sebagai individu yang siap kerja secara psikologis.

Pelatihan efikasi diri dalam bidang pekerjaan yang diberikan kepada subjek penelitian telah meningkatkan kemauan mereka untuk bekerja keras dalam menghadapi persaingan di dunia kerja, dan sekaligus meningkatkan keyakinan mereka tentang kemampuan yang selama ini telah dimiliki. Di samping kelebihan tersebut, penelitian ini masih mempunyai kelemahan, terutama dalam pelaksanaan pelatihan, materi dan media yang digunakan. Pelaksanaan pelatihan dilakukan mulai pukul 14:00, sehingga factor kelelahan dapat mempengaruhi jalannya penelitian. Materi pelatihan hanya memodifikasi dari materimateri yang sudah ada dan disesuaikan dengan kepentingan penelitian. Sedangkan media peratihan masih menggunakan $\mathrm{OH}$, belum memanfaatkan teknologi audio-visuai (misainya LCD).

Hasil analisis data dan pembahasan menunjukkan bahwa pelatihan efikasi diri daiam bidang pekerjaan mampu untuk meningkatkan kesiapan kerja calon tenaga kerja, sehingga saran yang diajukan adalah pelatihan efikasi diri daiam bidang pekerjaan ini dapat diberikan kepada calon tenaga kerja dari berbagai tingkat pendidikan, misalnya SMU/SMK maupun D III, karena jumlah pengangguran dari level pendidikan ini lebih banyak dibandingkan dengan sarjana dengan beberapa modifikasi disesuaikan dengan kondisi subjek. Pelaksanaan pelatihan lebih baik dilakukan sejak pagi hari, sehingga factor kelelahan dapat dikurangi. Materi pelatihan diusahakan tidak hanya modifikasi dari materi yang telah ada, tetapi sedapat mungin diciptakan materi-materi baru yang lebih sesual dengan konteks penelitian. Media pelatihan sebaiknya juga menggunakan teknologi audio-visual, misalnya LCD, sehingga perhatian peserta terhadap materi pelatihan lebih tinggi.

\section{Daftar Pustaka}

Azwar, S. (1998). Validitas dan reliabilitas. Yogyakarta: Pustaka Pelajar Bandura, A. (1977). Self Efficacy: Toward a unifying theory of behaviorai change. $P_{5 y-}$ chological review, 84,2, 191-215

(1986). Socialfoundation of thought \& action : a social cognitive theory. New Jersey: Prentice-Hall

(1997). Self efficacy: the exercise of control. New York: Freeman

BPS (Biro Pusat Statistik). (2001). Employment statistics, population \& type of activity (1997-2000) and unemployment by educational attainment (1997-2000).

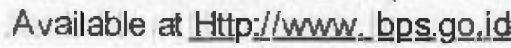

Bemardin, H. J. \& Russel, J. E. A (1998). Human resource management: an ex- 
periential approach. New York : Mc Graw-Hill

Casey, A. E. (2002). Work readiness assessment ready for testing. Retrieved from http://www. aecf. org/job in itiativel wreagady.htm

Cook, J. \& Campbell S. (1979). Quasi experimentation: design, issues \& analysis. New York : Harper \& Row

Hadi, S. (2000). Isu uji asumsi. Disampaikan dalam seminar kontroversi penggunaan prinsip-prinsip statistik. Diselenggarakan oleh Bagian Umum dan Eksperimen Fakultas Psikologi UGM pada tanggal 22 Juli 2000 di Gedung Pertemuan UC UGM (tidak diterbitkan). Yogyakarta: Fakullas Psikologi UGM

Hadi, S. \& Pamardiningsih, Y. (2000). Seri Program Statistik-Versi 2000 (tidak diterbitkan).Yogyakarta: Universitas Gadjah Mada

Hardjanto ${ }_{i}$ L. (1997). Hubungan antara efikasi diri dan sikap kompebitif superiority pada siswa. Skripsi (tidak diterbitkan). Yogyakarta: Fakultas Psikologi UGM
Hersey, P. \& Blanchard K H. (1993). Management of organization behavior: utilizing human resource, $6^{\text {th }}$ Ed. Englewood Cliff. New York: PrenticeHall

Pajares $_{\text {i }}$ F. (2002a). Self-efficacy beliefs in academic contexts: an outlines. Retieved month, day, year from hittp:ll WWw: emory.edu/EDUC ATIONN/mfpl efflalk.html

(2002b). Overview of social cognitive theory and of self efficacy. Retrieved month, day, year, from http II www:emory enduiED eff.html

Pintrinch, P. \& Schunk, D. (1996). Motivation in education:theory, research \& application, Ch. 3. NY: Prentice-Hall

Sagir, S. (1984). Kecenderungan kehidupan dindonesia menjelang tahun 2000 dan implikasinya terhadap pendidikan. Jakarta : Depnaker RI

Wahyono T. (2001). Ef ektivitas pelatihan persiapan kerja untuk meningkatkan kematangan vokasional pada remaja. INSAN Media Psikologi vol 3 No. 2, halaman 32-34

\section{$\operatorname{ros} \cos \cos c \alpha$}

